\title{
Swyer syndrome with progressive virilization in a Sri Lankan child
}

\author{
*Fathima Raihana Hashim ${ }^{1}$, Shamya de Silva², Malik Samarasinghe ${ }^{3}$
}

Sri Lanka Journal of Child Health, 2020; 49(4): 401-403

DOI: http://dx.doi.org/10.4038/sljch.v49i4.9277

(Key words: Swyer syndrome, gonadoblastoma, virilisation)

\section{Background}

Swyer syndrome or 46, XY complete gonadal dysgenesis, is a rare disorder of sex development (DSD) with a reported incidence of 1:80,000. Characteristic features are a female phenotype with normal female external genitalia, normal or hypoplastic Müllerian structures, dysgenetic gonads and a 46, XY karyotype ${ }^{1}$. Most present during adolescence with primary amenorrhea or delayed puberty ${ }^{2}$. Symptomatic abdominal masses and progressive virilization are rarer presentations. There are a few case reports of Swyer syndrome with virilizing gonadoblastoma ${ }^{3,4,6}$. To our knowledge, this is the first report from Sri Lanka of a patient with Swyer syndrome presenting with progressive virilization.

\section{Case report}

A 12-year old girl was referred for evaluation of progressive hoarseness and increasing facial hair of 12-month duration. Her perinatal period was unremarkable and she was registered as a girl. There was no family history suggestive of a DSD. She had been well until the current presentation and lacked constitutional symptoms.

Her height and weight were on the 50th percentile. She was hirsute and hoarse and had a masculine body habitus. She was not cushingoid, lacked a Turner phenotype and had stage II thelarche. Examination of the systems was normal. Genital examination revealed stage III pubarche, a $4 \mathrm{~cm}$ phallus and two perineal openings (Prader stage 1). There were no palpable gonads.

\footnotetext{
${ }^{1}$ Teaching Hospital Karapitiya, Sri Lanka, ${ }^{2}$ Professorial Paediatric Unit, Lady Ridgeway Hospital for Children, Colombo, Sri Lanka, ${ }^{3}$ Professorial Surgical Unit, Lady Ridgeway Hospital for Children, Colombo, Sri Lanka *Correspondence: raihana.nuzair@gmail.com

The authors declare that there are no conflicts of interest

Personal funding was used for the project.

Open Access Article published under the Creative

Commons Attribution CC-BY (CC) (†) License
A pre-pubertal uterus, possible bilateral small ovaries and normal adrenal glands were seen ultrasonically. Recent onset virilization in a girl with a normal abdominal ultrasound and an advanced bone age (15 years) led to a presumptive diagnosis of non-classical congenital adrenal hyperplasia $(\mathrm{CAH})$ and hydrocortisone was started pending biochemistry and karyotype.

Biochemical investigations showed normal ACTHstimulated 17OHP levels (Table 1) which excluded $\mathrm{CAH}$. The raised gonadotrophin levels with no evidence of puberty were suggestive of the undescended gonads being dysgenetic. The karyotype was 46, XY and was available only a month later. A 46, XY phenotypic female with Mullerian structures and having evidence of dysgenetic gonads revised the diagnosis to Swyer syndrome or 46, XY complete gonadal dysgenesis.

Malignant transformation of the undescended gonads to a gonadoblastoma was clinically suspected and was supported by an elevated tumour marker. Further imaging revealed a well-defined left-sided calcified pelvic mass located between the uterus and rectum.

At laparotomy, a well-circumscribed left-sided pelvic mass measuring $7 \mathrm{~cm} \times 4 \mathrm{~cm} \times 3 \mathrm{~cm}$ was removed. Fibrotic tissue suspected to be the right streaky gonad was also excised while preserving the uterus. Histology showed bilateral gonadoblastoma and dysgerminoma in the left gonad. She received chemotherapy and follow up pelvic scans and tumor markers showed no evidence of recurrence.

At the last clinic visit, she had dramatic reduction in facial hair and did not appear masculine. However, she had no thelarche and the phallus had regressed in size. One year after chemotherapy, hormone replacement therapy with oestrogen was started. 
Table 1: Hormonal assay and biochemistry at diagnosis and during follow up

\begin{tabular}{|l|c|c|c|}
\hline & Initial investigations & $\begin{array}{c}\text { Post op } \\
\text { - 6 weeks later }\end{array}$ & $\begin{array}{c}\text { 1 year after } \\
\text { chemotherapy }\end{array}$ \\
\hline ACTH-stimulated 17OHP (nmol/L) & & & \\
0 min & 7.7 & & \\
$30 \mathrm{~min}$ & 9.9 & & \\
\hline Cortisol $(\mathrm{nmol} / \mathrm{L})$ & 304 & & \\
0 min & 368 & & \\
$30 \mathrm{~min}$ & 456 & & \\
$60 \mathrm{~min}$ & $30.55(10-50)$ & \\
\hline 9am ACTH $(\mathrm{pg} / \mathrm{ml})$ & $5.5(0.27-4.6)$ & & \\
\hline DHEAS $(\mu \mathrm{mol} / \mathrm{L})$ & $10.04($ Tanner 3, male $)$ & & \\
\hline Testosterone $(\mathrm{nmol} / \mathrm{L})$ & 30.89 & & \\
\hline FSH $(\mathrm{IU} / \mathrm{L})$ & 33.35 & & \\
LH $(\mathrm{IU} / \mathrm{L})$ & $19.3(<7.0)$ & & \\
\hline Beta hCG $(\mathrm{mIU} / \mathrm{L})$ & $1.2(<8.5)$ & & \\
\hline Alpha fetoprotein $(\mu \mathrm{g} / \mathrm{ml})$ & $46, \mathrm{XX}$ & & \\
\hline Karyotype & & & \\
\hline
\end{tabular}

\section{Discussion}

Swyer syndrome is caused by errors in sex determination during embryogenesis. SRY gene mutations account for about $10-15 \%$ of Swyer syndrome. But a genetic diagnosis is not achieved in about $50 \%$ of patients with gonadal dysgenesis ${ }^{1}$. Patients are normal-to-tall, present with underdeveloped breasts, normal pubarche and female external genitalia. Our patient had all the above features in addition to a 46, XY karyotype, normal Mullerian structures and dysgenetic gonads which supported the diagnosis of this syndrome. Virilization occurs following the development of androgen-secreting gonadoblastoma in the dysgenetic gonads. Our patient presented with recent onset virilization, elevated testosterone of gonadal origin and elevated $\beta$-hCG levels. There are a few reported cases of $46, \mathrm{XY}$ females with similar presentations $\mathrm{s}^{3-5}$. In a case series, the median age of diagnosis of dysgerminoma was 17 years $^{2}$.

The differential diagnoses of a female presenting with recent onset of virilization are virilizing tumors in a $46, \mathrm{XX}$ or $46, \mathrm{XX} / 46, \mathrm{XY}$ ovo-testes. In ovotesticular DSD there is some degree of genital ambiguity from birth since the functioning testes produces testosterone causing some degree of virilization. Testosterone biosynthetic defects such as $17 \beta$-hydroxysteroid dehydrogenase type 3 and $5 \alpha$-reductase type 2 deficiencies also present with progressive virilization at puberty. These individuals also have some degree of genital ambiguity at birth. The dysgenetic gonads are at increased risk of gonadoblastoma and dysgerminoma, and the risk is estimated to be around $15 \%-35 \%$. Therefore, early diagnosis and appropriate management is vital.

Our patient presented with evidence of malignancy and warranted a staged surgery. Advanced disease stages necessitate adjuvant chemotherapy.
Dysgerminomas are very sensitive to chemotherapy. Our patient received chemotherapy with no evidence of recurrence on follow up to 24 months after presentation. Swyer syndrome is a rare DSD which should be considered in adolescents presenting with amenorrhea, delayed puberty or progressive virilization. Availability of investigations such as FISH for $\mathrm{Y}$ chromosome would have facilitated a quicker diagnosis, avoidance of unnecessary medications and earlier initiation of appropriate therapy.

\section{Acknowledgements}

We gratefully acknowledge Dr. SA Gunarathne, Consultant Histo-pathologist, Lady Ridgeway Hospital, Colombo and Dr. Y Ubaiythullah, Consultant Radiologist, Lady Ridgeway Hospital, Colombo

\section{References}

1. Ahmed SF, Bashamboo A, Lucas-Herald A, McElreavey K. Understanding the genetic aetiology in patients with XY DSD. British Medical Bulletin 2013; 106: 67-89.

https://doi.org/10.1093/bmb/ldt008

PMid: 23529942

2. Michala L, Goswami D, Creighton SM, Conway GS. Swyer syndrome: Presentation and outcomes. BJOG 2008; 115(6): 737-41.

https://doi.org/10.1111/j.14710528.2008.0 1703.x

PMid: 18410658

3. Lange A, Wieacker P, Schnabel R, Schweikert HU, Schumann K. XY gonadal dysgenesis (Swyer syndrome) 
with gonadoblastoma. Zentralbl Gynakol. 1998; 120(11):555-8.

4. Barakat BY, Ances IG, Tang CK, Fajer AB. 46, XY gonadal dysgenesis with secondary amenorrhea, virilization, and bilateral gonadoblastoma. Southern Medical Journal 1979; 9:1163-5.

https://doi.org/10.1097/000076111979090

00-00025

PMid: 572994

5. Kanagal DV, Prasad K, Rajesh A, et al. Ovarian gonadoblastoma with dysgerminoma in a young girl with 46, XX karyotype: A Case Report. Journal of Clinical and Diagnostic Research 2013; 7(9):2021-2.

https://doi.org/10.7860/JCDR/2013/6412.

3393

PMid: 24179931 PMCid: PMC3809670 